\title{
Reply to the letter
}

\author{
Naoyuki Hirata ${ }^{1} \mathbb{D} \cdot$ Michiaki Yamakage $^{1}$
}

Received: 28 September 2020 / Accepted: 3 October 2020 / Published online: 31 October 2020

(c) Japanese Society of Anesthesiologists 2020

Keywords Cardiovascular surgery $\cdot$ Anesthetic management $\cdot$ COVID-19 pandemic

To the Editor:

We are grateful to Dr. Magoon for the helpful comments on our article [1]. As he pointed out in the letter to the editor, we have not referred to pulmonary-vascular consequences in the patients with COVID-19. Prolonged hypoxia and mechanical ventilation can cause pulmonary hypertension $(\mathrm{PH})$ in patients with COVID-19. PH per se is a significant predictor of adverse cardiopulmonary outcome in surgical patients as reflected by increased postoperative complications in patients with co-existing high-risk clinical and surgical characteristics [2]. Anesthesiologists should provide appropriate anesthesia and analgesia with avoidance of exacerbating factors of PH (e.g., hypoxia, hypercapnia, acidosis, and hypothermia) and with administrating intravenous vasodilators (e.g., milrinone, nitroprusside, and nitroglycerine) [2]. While a specific strategy against $\mathrm{PH}$ in patients with COVID-19 has not been established, the use of nitric oxide may be a strategy in addition to the above conventional approaches [3].

The letter from Dr. Magoon reminds us of the importance of pulmonary-vascular consequences during the COVID-19 pandemic.
Funding The authors have no financial interests in products related to this article.

\section{References}

1. Hirata N, Yamakage M. Cardiovascular considerations for anesthesiologists during the COVID-19 pandemic. J Anesth. 2020. https://doi.org/10.1007/s00540-020-02852-1 ((Online ahead of print)).

2. Minai OA, Yared JP, Kaw R, Subramaniam K, Hill NS. Perioperative risk and management in patients with pulmonary hypertension. Chest. 2013;144:329-40.

3. Moron BA, Gladwin MT, Bonnet S, Perez VDJ, Perman SM, Yu $\mathrm{PB}$, Ichinose F. Perspectives on cardiopulmonary critical care for patients with COVID-19: From members of the American heart association council on cardiopulmonary, critical care, perioperative and resuscitation. J Am Heart Assoc. 2020;9:e17111.

Publisher's Note Springer Nature remains neutral with regard to jurisdictional claims in published maps and institutional affiliations.

This reply refers to the comment available online at https://doi. org/10.1007/s00540-020-02869-6.

Naoyuki Hirata

naohirata@mac.com

1 Department of Anesthesiology, Sapporo Medical University

School of Medicine, South 1, West 16, Chuo-ku, Sapporo,

Hokkaido 060-8543, Japan 